\title{
Application of a Zoning Methodology for Groundwater Suitability on Islands, a Case Study of Pingtan Island, China
}

\author{
Xiaomin Teng ${ }^{1}$, Yuxi $\mathrm{Li}^{2}$, Panlin $\mathrm{Li}^{1}$ and Wanglin $\mathrm{Li}^{1 \text {,* }}$ \\ 1 School of Water Conservancy and Environment, University of Jinan, Jinan 250022, China; \\ sdnydxtxm@163.com (X.T.); 17854174039@163.com (P.L.) \\ 2 College of Hydrology and Water Resources, Hohai University, Nanjing 210098, China; 15044030896@163.com \\ * Correspondence: cswlwe@163.com; Tel.: +86-133-5531-9069
}

Citation: Teng, X.; Li, Y.; Li, P.; Li, W. Application of a Zoning Methodology for Groundwater Suitability on Islands, a Case Study of Pingtan Island, China. Water 2021, 13, 2000. https://doi.org/10.3390/w13152000

Academic Editors: Chunhui Li,

Zoe Li, Yurui Fan, Celso Augusto Guimarães Santos and Junliang Jin

Received: 10 May 2021

Accepted: 20 July 2021

Published: 21 July 2021

Publisher's Note: MDPI stays neutral with regard to jurisdictional claims in published maps and institutional affiliations.

Copyright: (c) 2021 by the authors. Licensee MDPI, Basel, Switzerland. This article is an open access article distributed under the terms and conditions of the Creative Commons Attribution (CC BY) license (https:// creativecommons.org/licenses/by/ $4.0 /)$.

\begin{abstract}
A groundwater function evaluation systems and associated model was applied to Pingtan Island in China, to support future development, use and protection of groundwater. Groundwater function was assigned to resource, ecology and geological environmental functions, and then further sub-divided, based on hydrogeological conditions, development status, planning and Chine policy requirements. At the same time, it is the first time to try to apply the technical requirements for the division of groundwater resources in island areas. According to the planning and utilization of groundwater resources in Pingtan Island, established a second-level system of shallow groundwater function zoning. Then, by comparing the strong and weak relationships among the groundwater resource function, ecology function, and geological environment function, developed a scoring system of the shallow groundwater function zoning. The division of shallow groundwater function zones in Pingtan Island was finally carried out. The zoning result will play an essential role in the future development, utilization, and protection of groundwater in Pingtan Island. At the same time, it provides the first example for the application of groundwater function zoning in island areas and improves the theoretical results of groundwater function zoning.
\end{abstract}

Keywords: groundwater; groundwater management; groundwater function evaluation; groundwater function zoning; ArcGIS

\section{Introduction}

Groundwater resource refers to the amount of underground water that can meet the needs of human production and life in a period and can be replenished and restored every year [1]. It is an important part of water resources. Groundwater resources play an essential role in human production and living, ecological environment and geological environment. To meet the needs of people's life and economic development, the development scale of groundwater resources is increasing in China. In exploitation, and utilization of groundwater resources, there are also some problems such as groundwater level decline, seawater intrusion and land subsidence [2]. The excessive exploitation and utilization of groundwater seriously affects the groundwater function and threatens the long-term development of society and the economy.

Groundwater management is particularly important. To effectively manage groundwater resources, many scholars in China put forward the method of groundwater function zoning. Groundwater function refers to the quality and quantity of groundwater and its changes in space and time, the role or effect on human society and the environment, including Groundwater resource function (referred to as 'resource function'), Groundwater eco-environmental function (referred to as 'ecology function') and Groundwater geo-environmental function (referred to as 'geological environment function'). Groundwater Function Zoning is based on the evaluation of subdivision units; the contour maps of relevant indicators are drawn to delineate groundwater function zones of different types of attributes. It provides a scientific basis for sustainable utilization of groundwater resources 
and planning of geological environment and ecological environment protection. Groundwater management and protection must be based on functional zoning, and it is necessary to clarify what the groundwater in various regions is for and classify the protection and management by zoning. Identify its leading functions and protection standards. Since the beginning of the 20th century, studies on groundwater functional zoning have been carried out in China. In 1998, Xu was the first to discuss the purpose, principles, and methods of groundwater functional zoning [3]. In 1999, Shi and Sun mainly discussed the application of grey clustering analysis in groundwater functional zoning and illustrated it with examples [4]. Tang established a two-level system of shallow groundwater function zoning system in 2004 according to its functions in resources, ecology, and geological environment [5]. In 2005, according to the arrangement of the national groundwater resources planning, the Ministry of Water Resources compiled the Technical Outline for Groundwater Function Zoning (hereinafter referred to as the "Technical Outline") according to which many provinces have divided their groundwater function zones. In 2006, the Ministry of Land and Resources compiled the Technical Requirements for Groundwater Function Evaluation and Zoning (hereinafter referred to as the "Technical Requirements"), and carried out groundwater function zoning in plain areas of Northwest, Northeast and North China on based. According to the "Technical Outline" and "Technical Requirements," many scholars have divided the groundwater function zones into many regions in China. For example, Liu and Li have divided the groundwater function zones in Jilin Province according to the "Technical Outline" and the current distribution of groundwater resources in Jilin Province [6]. Cao et al. divided the groundwater in Quanzhou into functional zones according to the technical requirements and the functional distribution characteristics of Quanzhou groundwater in terms of resources, ecology, and geological environment [7].

Abroad, there are no groundwater function regionalization research reports, but in the protection of groundwater resources are mostly give full consideration to the groundwater in the aspect of resources, ecology, and geological environment function, such as Arizona (USA) by setting up effective administrative zone, underground water pipe of the strict rules and regulations, and make sustainable development and utilization of groundwater resources [8-10]. To protect its groundwater resources, according to the development and utilization of groundwater in various regions of the country, Britain has delimited groundwater source protection areas [11]. The scarcity of surface water and irregular distribution in the time and space of rainfall, typical of the Mediterranean environment, together with the extensive limestone outcrops, Fernández-Mejuto has said that have made groundwater an essential resource for the southeast of Spain [12]. Groundwater is one of the most precious water resources in this Sahara region, he has assessed the knowledgedriven techniques employed to develop a model to integrate the multicriteria derived from geologic, geomorphic, structural, seismic, hydrologic, and remotely sensed data [13]. Lyra et al. presented an integrated modeling system to evaluate the quantity and quality of water resources of coastal agricultural watersheds. The proposed modeling system could be used as a tool for the simulation of water resource management and climate change scenarios [14].

Due to the unreasonable development and utilization of groundwater resources, many ecological and geological environmental problems have been caused. Therefore, China has formulated many laws and regulations to regulate the growth and utilization of groundwater and protect groundwater resources. These laws and regulations include "Water Method," "Regulations for the Implementation of the Water Permit System," and "Notice on the zoning of groundwater overexploitation." These laws and regulations protect groundwater resources to a certain extent, but these are remedial management measures and have not fundamentally solved the unreasonable development of groundwater resources. Therefore, we need to comprehensively consider the functional attributes of groundwater, formulate the development and utilization plan of groundwater resources in the initial stage of groundwater development and utilization, and divide the functional areas of groundwater. The groundwater function zoning in this paper is based on 
China's groundwater policy framework. In 2006, the Ministry of Land and Resources compiled "Groundwater function evaluation and technical zoning requirements" According to the technical requirements, the functional zoning is mainly applicable to the Quaternary groundwater system in Northwest China, North China, and Northeast China. It is not specified that islands can be used it [15-17].

Pingtan Island is located in the eastern sea area of Fujian Province and east of the Taiwan Strait. It is the nearest place between the mainland of China and Taiwan Island. Due to its unique geographical location, the state has built it into a comprehensive experimental area for the economic and scientific development of the west coast of the Taiwan Strait and strengthened the integration and exchanges with the economy, culture, and society of the Taiwan region China. However, Pingtan Island is narrow in the territory, large in evaporation, and short in the stream, all of which flow into the sea alone. Manyrainwater resources are not effectively utilized, resulting in a shortage of water resources on the island and seriously restricting the socio-economic development of Pingtan Island. On the one hand, people pay attention to the development and utilization of surface water resources by constructing water conservancy projects and other methods. On the other hand, the development and utilization of shallow groundwater resources have also become a meaningful way to alleviate the shortage of water resources on the island. Therefore, the division of shallow groundwater function zones in Pingtan Island will play a reference and guidance role in the rational development, utilization, and protection of groundwater in Pingtan Island in the future, which has important practical significance and application value.

The management of groundwater rights in the United States is not as perfect as the management of surface water rights. There are four forms of water rights management, not all states use groundwater reasonably. Japan does not have a comprehensive law on the use of groundwater and its water rights. Chapter 18 of 'Agenda 21' adopted by the United Nations Conference on Environment and Development, 'Comprehensive Approaches to Protect the Quality and Supply of Freshwater Resources, Water Resources Development, Management and Utilization', points out that fresh water resources are the basic components of the Earth's Water Circle and an indispensable part of all terrestrial ecosystems. All aspects of life need water. The overall goal is to ensure that all people on the earth get enough quality water, while maintaining the hydrological, biological and chemical functions of the ecosystem, adjusting human activities within the limits of natural carrying capacity, and preventing water diseases. Due to the general lack of freshwater resources in many regions of the world and the gradual destruction, the pollution is becoming more and more serious, coupled with the incompatibility of activities, it is necessary to make overall planning and management of water resources. For the better capitalize and develop groundwater resources of Pingtan Island, establish a shallow groundwater function regionalization scoring system, to complete it groundwater function zoning. The zoning results will play a guiding role in the rational development, utilization, and protection of groundwater in Pingtan Island in the future and have important practical significance and application value. This method is more perfect in index selection and function evaluation system, and the result of zoning is more in line with the reality. At the same time, it can provide examples for the utilization and management of groundwater in other areas. As an important way to solve the shortage of water resources in islands.

\section{Study Area}

Pingtan Island, located in the east sea of Fuzhou City, Fujian Province, China, extends from $25^{\circ} 15^{\prime}$ to $25^{\circ} 45^{\prime} \mathrm{N}, 119^{\circ} 32^{\prime}$ to $120^{\circ} 10^{\prime} \mathrm{E}$. The island covers an area of $295 \mathrm{~km}^{2}$ and is the largest island in Fujian Province. The satellite map is shown in Figure 1. The topography of Pingtan Island is mainly a Marine plain with relatively flat terrain. In the north, Pingtan Island is distributed in three NNE-striding hilly areas, among which there are Plains such as Luyangpu, Shangpengyang, Lianjiupu, and Dawopu. In the middle of Pingtan Island, there are Longwangtoupu, Qilipu, and other coastal plains. South has more low hills, hills have the Yangzhongyangpu, Cangxiayang, Dongkunyang, and other small plains. Pingtan 
Island is characterized by the South Asian tropical maritime monsoon climate and the same season of rain and heat, with an average annual precipitation of $1180.2 \mathrm{~mm}$, water surface evaporation of $1330 \mathrm{~mm}$, and land surface evaporation of $550 \mathrm{~mm}$ [17]. Pingtan Island is a region with severe water shortages and drought. Pingtan Island is narrow, and its water system is underdeveloped. It is seasonal rivers with short streams flowing into the sea, and the surface water volume is minimal $[18,19]$.

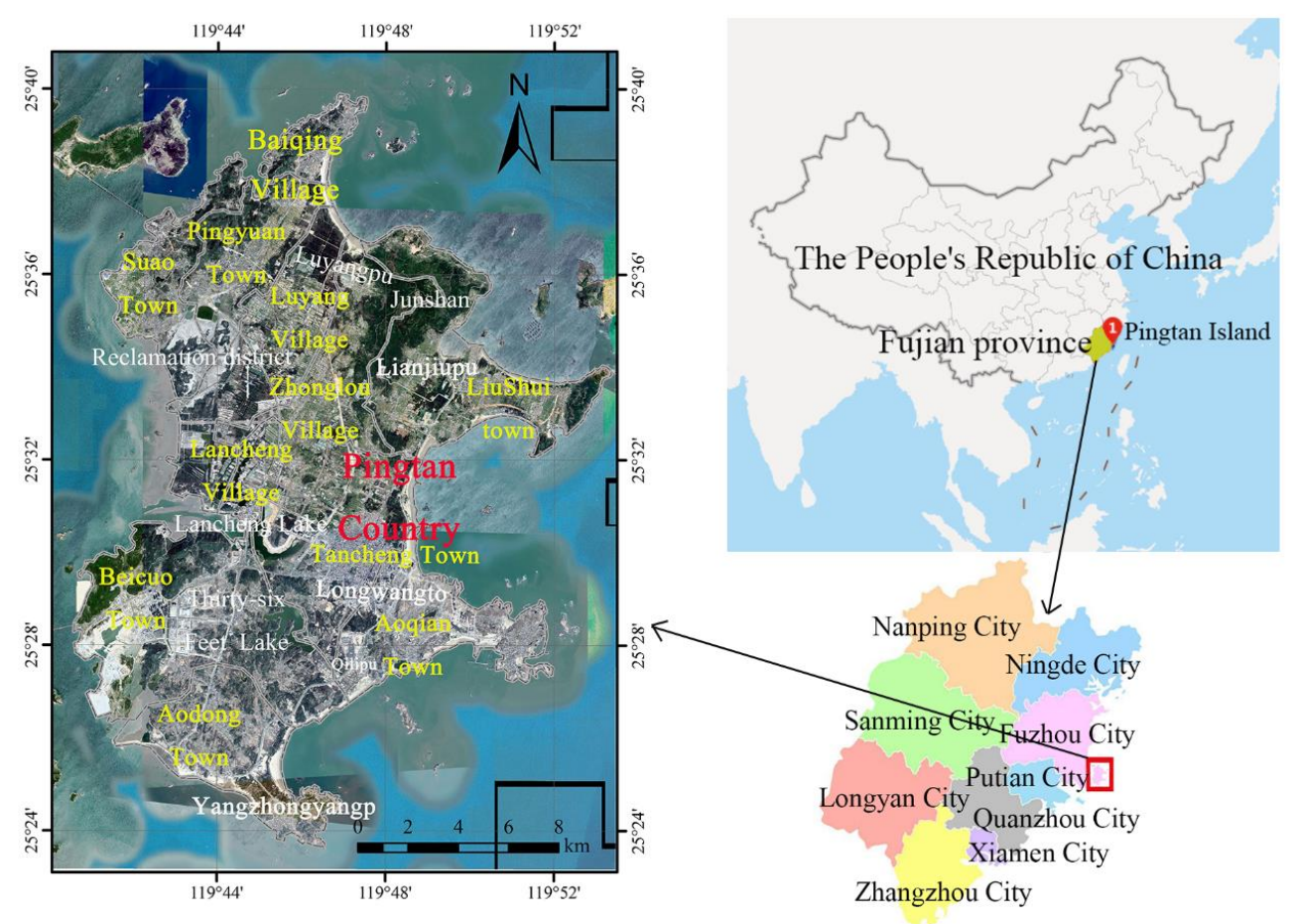

Figure 1. Pingtan Island Satellite map.

According to the occurrence conditions of groundwater in Pingtan Island, the shallow groundwater in Pingtan Island is divided into two types: pore water of loose rock and fissure water of bedrock. According to the water inflow of a single pore, the pore water of loose rocks in the study area can be divided into three grades according to the water abundance: the areas with abundant underground water are mainly distributed in Luyangpu, Qilipu, Lianjiupu, and Longwangtoupu. The middle area of underground water volume is mainly distributed in Dawopu, Fengyang, Yanxiapu, Cangxiayang, Dongkunyang, and Zhongyang Yangpu; The areas with poor underground water quantity are mainly distributed in the hilly and valley areas of Aodong, Suao, Baiqing, and Tandong. Bedrock fissure water is mainly distributed in hills, terraces, and slopes.

\section{Methods}

\subsection{Groundwater Function Evaluation System}

\subsubsection{Construction of Groundwater Function Evaluation System}

To understand the groundwater function of the study area from different levels, the groundwater function was evaluated from following four levels: system layer, function layer, attribute layer, and element layer, which according to the development and utilization status of shallow groundwater in Pingtan Island and the requirements of groundwater function evaluation in Technical Requirements of China.

The system layer refers to the target of shallow groundwater function zoning in the study area; the function layer consists of three indexes of resource function, ecology function, and geological environment function. 
For the evaluation index system of resource function, in "Technical requirements" resource function includes four attribute indexes. This paper selects three attribute indexes, namely resource occupancy, resource regeneration and resource availability:

(1) In "Technical Requirements", resource occupancy includes four evaluation indexes. In this paper, the supply resources occupancy percentage and storage resources occupancy percentage are selected as two evaluation indexes. The supply resources occupancy percentage refers to the ratio of the supply resource module obtained from the region to the average supply resource module of the study area. The storage resources occupancy percentage refers to the ratio of the groundwater storage resource modulus of the evaluated subregion to the average storage resource modulus of the study area. Since there is no large-scale and stable water transfer from outside the study area, the index of supply resources occupancy from outside the study area is discarded. The utilizable resource occupancy index refers to the ratio between the utilizable resource modulus of groundwater in the evaluated subdivision or unit and the average utilizable resource modulus of the study area. Since this index and the recoverable resource modulus index have the same expression meaning, and there is a repeated and multiple relationship between them, the utilizable resource occupancy index is discarded.

(2) In "Technical Requirements", there are four evaluation indexes for resource regeneration. In this paper, three evaluation indexes are selected, including Replenishment and renewal rate, balance rate of replenishment and supply availability rate. The replenishment and renewal rate refers to the ratio of the replenishment resource modulus to the storage resource modulus in the evaluated zone. The balance rate of replenishment refers to the ratio of the average annual recharge in the last 5-12 years to the corresponding average annual exploitation in the evaluated subdivision or unit. The supply availability rate refers to the ratio of the recharge resource modulus to the available resource modulus of the evaluated subdivision or unit. Since the expression meanings of rainfall recharge rate and supply availability are similar, in order to avoid index duplication, the index of rainfall recharge rate is discarded. Resource regulation refers to the response of the groundwater table to precipitation, recharge and exploitation. As the water level monitoring work in the study only covers the Luyangpu in the north of Pingtan Island, there is no groundwater level monitoring data in other areas of Pingtan Island, which is limited by the collected data, so we abandon the resource regulatory evaluation index.

(3) In "Technical Requirements", resource availability includes four evaluation indexes. In this paper, three evaluation indexes including available resource modules, degree of resource exploitation and resource quality index are selected. The available resource modules refers to the recoverable groundwater resources per unit area of the evaluated subregion. The degree of resource exploitation refers to the ratio of the average annual usable amount in the last 5 years to the corresponding actual exploitation amount in the evaluated area. The resource quality index refers to the groundwater quality level of the evaluated subdivision or unit. The evaluation index of available reserve modulus is omitted because of the similar significance and multiples between available reserve modulus and storage resource occupancy.

For the evaluation index system of ecology function, in "Technical requirements", ecology function consists of four attribute indexes. In this paper, the following three attribute indexes are selected, the Vegetation environmental maintenance, the landscape environment maintenance and Land environmental maintenance:

(1) The unselected attribute index of ecology function is the correlation of water environment, which includes the degree of correlation of water environment mineralization and groundwater and the degree of correlation of nitrogen and phosphorus index change and groundwater. Water environmental relevance refers to the effect of groundwater on the environmental quality of surface wetlands or lakes. Since there is only one medium-sized reservoir on Pingtan Island, with a total reservoir capacity 
of 27 million square meters, the reservoir area accounts for less of the total area of the study area, and there is also a lack of water sample quality testing data for the reservoir, so the relevance of water environment is no longer considered.

(2) In "Technical Requirements", the vegetation environmental maintenance includes three evaluation indexes. In this paper, the oasis change and groundwater degree of correlation is selected as an evaluation index. The degree of correlation between oasis change and groundwater refers to the degree of correlation between the status of artificial oasis (coverage rate or its index) in the evaluated area and the change of groundwater level in the same period. According to the vegetation types of land surface, woodland, arable land, grassland and construction land are all included in the scope of artificial oasis. Because the artificial oasis contains the natural plant and grassland, the two evaluation indexes of the degree of correlation between grassland change and groundwater and the degree of correlation between natural plant change and groundwater were abandoned.

(3) In "Technical Requirements", the landscape environment maintenance index includes two evaluation indexes, and this paper chooses one in total, which is the lake environment and groundwater degree of correlation. The lake environment and groundwater degree of correlation refers to the degree of correlation between the condition of limnology environment (water depth and area) in the evaluated area and the change of groundwater level in the same period. Since Pingtan Island has one medium-sized lake and several small reservoirs, there is a recharge relationship between reservoir and shallow groundwater, so the index of correlation between lake environment and groundwater is selected. The degree of correlation between landscape change index and groundwater refers to the degree of correlation between the unique hydrogeological landscape change index (area or spring discharge) and groundwater change in the same period in the evaluated region. Since this index is mainly related to reservoirs and lakes in the study area, and has similar expression meaning with the degree of correlation between lake-marsh environment and groundwater, in order to avoid repetition, the index of landscape change and the degree of correlation index of groundwater are abandoned.

(4) In "Technical Requirements", land environmental maintenance includes three evaluation indexes. In this paper, the and salinization and water level degree of correlation is selected as an evaluation index. The and salinization and water level degree of correlation refers to the degree of correlation between the salinization (degree) of the evaluated area and the variation of groundwater level in the same period. Because the plain area in the study area is mainly sandy soil layer, but there is no land desertification phenomenon, so the evaluation index of the degree of correlation between land desertification and groundwater is abandoned. Because the degree of correlation between land quality and groundwater is related to the mineralization degree of shallow groundwater and similar to the expression meaning of the degree of correlation between groundwater quality and water level in the deterioration of groundwater system, the evaluation index of the degree of correlation between land quality and groundwater is abandoned in order to avoid repetition.

For the evaluation index system of geological environment function, in "Technical Requirements", the geological environment function of shallow groundwater includes two attribute indexes. In this paper, only one attribute index of groundwater system deterioration is selected:

(1) Another attribute index of geological environment function is the stability of geological environment, which includes the degree of correlation between land subsidence and groundwater, cumulative recovery and elastic water release coefficient, annual average settlement and annual recovery, cumulative settlement and the drop of water level in the same period. These indicators are all related to land subsidence. Since there is no subsidence-related monitoring data in the study area, no geological disasters caused by subsidence have occurred in the study area, and the target of 
this study is shallow aquifer, the attribute index of geological environment stability is abandoned.

(2) In "Technical Requirements", the deterioration of groundwater system includes four evaluation indexes. In this paper, two evaluation indexes are selected, the degree of correlation between groundwater quality and water level and degree of correlation between seawater intrusion and groundwater. The degree of correlation between groundwater quality refers to the degree of correlation between groundwater quality (salinity or other indicators) in the evaluated subregion and the change of groundwater level in the same period. The water level and degree of correlation between seawater intrusion and groundwater refers to the degree of correlation between the intrusion of groundwater by Marine salt water and the change of groundwater in the same period in the evaluated subdivision or unit. Due to the scarcity of spring distribution and the lack of relevant data in the study area, the degree of correlation between spring change and groundwater was abandoned. Due to the lack of monitoring data of the whole water level in the study area, the ratio between the change rate of groundwater recharge and the change of groundwater level in the same period was abandoned.

Based on the Driving-State-Response aspect of groundwater in Pingtan Island, this paper selects 13 evaluation element indexes from the element indexes group provided in the Technical Requirements in China using empirical analysis and expert consultation. The functional zoning hierarchical structure of shallow groundwater in Pingtan Island is shown in Figure 2.

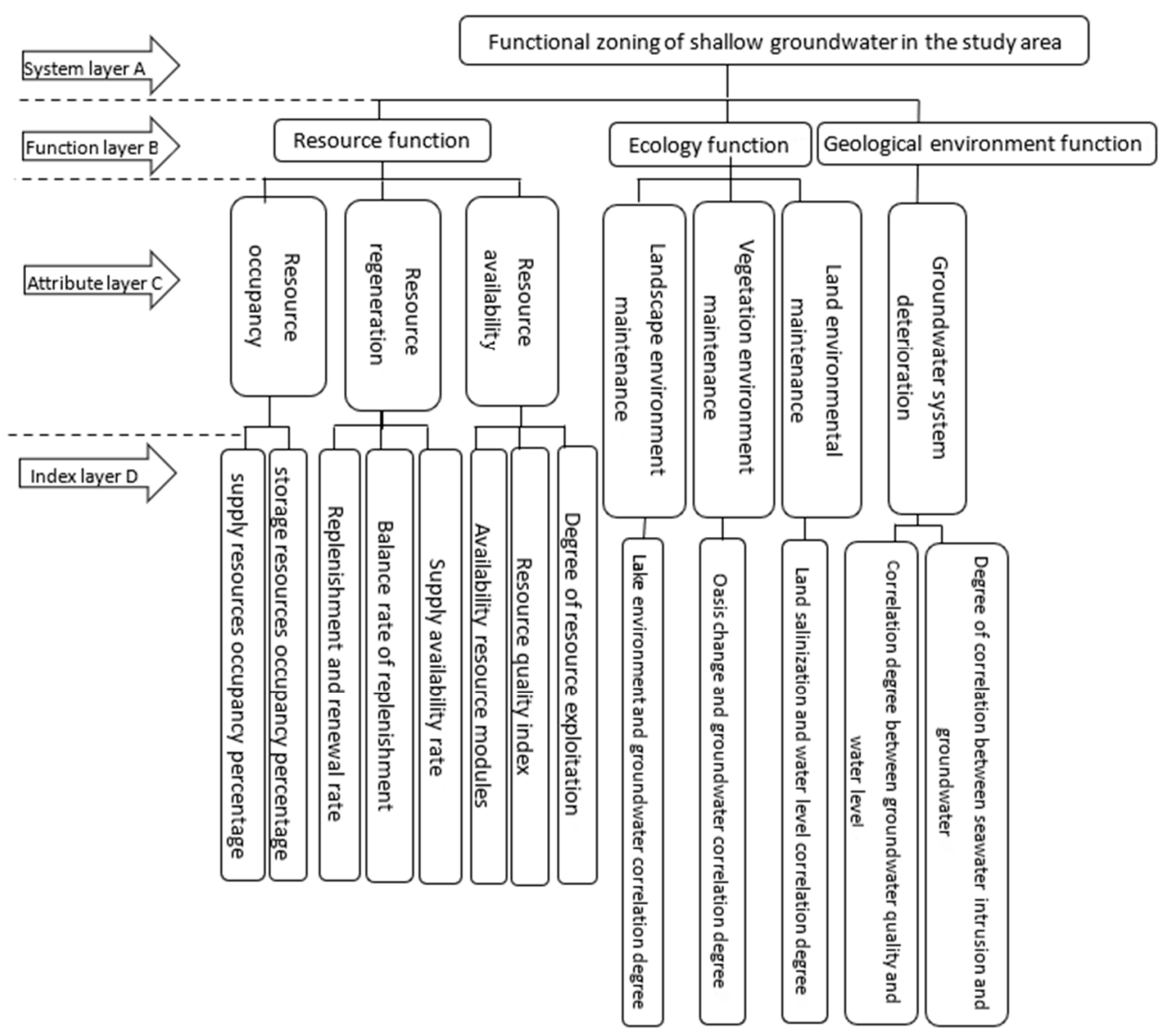

Figure 2. Functional zoning hierarchical structure of shallow groundwater in Pingtan Island. 


\subsubsection{Index Weight of Groundwater Function Evaluation System}

In this paper, the analytic hierarchy process was used to weigh the indexes of each layer. The weighting process of each evaluation index was calculated from the element index layer, attribute layer, function layer, and system layer from bottom to top.

\section{Constructing Pairwise Judgment Matrix}

The pairwise judgment matrix is constructed as follows: suppose that $C$ is the upper element, $x_{1}, x_{2}, \ldots, x_{n}$ is the next level of element dominated by the $C$ element. On a scale of 1 to 9 to assign $x_{1}, x_{2}, \ldots, x_{n}$, and the scale definition of 1-9 are shown in Table 1 . According to the requirement of judgment matrix construction, the judgment matrix of each element of index layer, attribute layer, and function layer to the upper element is constructed.

Table 1. Definition of scale of judgment matrix.

\begin{tabular}{cl}
\hline Scale & \multicolumn{1}{c}{ Meaning } \\
\hline 1 & Comparison of two factors, the two factors have the same importance \\
3 & Comparison of two factors, one factor is slightly more important than the other \\
5 & Comparison of two factors, one factor is obviously more important than the other \\
7 & Comparison of two factors, one factor is more important than the other \\
9 & Comparison of two factors, one factor is more extremely important than the other \\
$2,4,6,8$ & The median of two adjacent judgments above \\
\hline
\end{tabular}

Calculation of Weight Vector and Consistency Test

The relative weights of the compared elements $x_{1}, x_{2}, \ldots, x_{n}$ for the upper layer element $C$ are calculated by the judgment matrix, and the consistency test is carried out. Then, the consistency test is carried out on the weight vector. If the consistency ratio is less than 0.1 , it is considered that the judgment matrix passes the consistency test. On the contrary, it does not pass the test, and the judgment matrix should be revised.

\subsubsection{Construction of Function Comprehensive Evaluation Model}

To judge the total functional strength of a research area refers to synthesizing all factors under the influence of all single indicators. In this paper, the weighted arithmetic means synthesis model is applied, and the comprehensive evaluation index $R$ of each sub-region is calculated as shown in Equation (1):

$$
R=\sum_{i=1}^{n} a_{i} x_{i}
$$

where $R$ is the comprehensive evaluation index of function, $0 \leq R_{i} \leq 1$ (the higher $R$, the higher the functional strength), $a_{i}$ is the weight corresponding to the evaluation index and $x_{i}$ is evaluation parameter [the normalized interval value (0-1) of the numerical index data or the interval score value (0-1) of the non-numerical index data.]

According to Equation (1), $R$ values of indicators at all levels are calculated. For different target functions, the development and utilization prospects of groundwater corresponding to $R$ values are shown in Table 2 .

\subsection{Groundwater Functional Zoning System}

\subsubsection{Shallow Groundwater Functional Zoning System}

According to the development and utilization needs of groundwater in Pingtan Island, and considering the functions of the island's resources, ecology and geological environment, the second-level system of the shallow groundwater functional area in Pingtan Island was divided. The functional zoning system of shallow groundwater in the study area is shown in Figure 3. 
Table 2. Classification and significance of groundwater target function evaluation results.

\begin{tabular}{cccc}
\hline Function Name and Code & Comprehensive Evaluation Index $(\boldsymbol{R})$ & Functional Status & Utilization Prospect \\
\hline & $R>0.84$ & Strong & Scale mining \\
& $0.67<R \leq 0.84$ & Stronger & Moderate mining \\
Resource Function, $\mathrm{B}_{1}$ & $0.34<R \leq 0.67$ & Ordinary & Regulating mining \\
& $0.17<R \leq 0.34$ & Weak & Not suitable for mining \\
& $R \leq 0.17$ & Weaker & Prohibition of mining \\
& $R>0.84$ & Strong & Unavailability \\
& $0.67<R \leq 0.84$ & Stronger & Not suitable for use \\
& $0.34<R \leq 0.67$ & Ordinary & Conservation utilization \\
& $0.17<R \leq 0.34$ & Weak & Moderate utilization \\
& $R \leq 0.17$ & Weaker & Plan utilization \\
Ecology Function, $\mathrm{B}_{2}$ & $R>0.84$ & Strong & Prohibition of mining \\
& $0.67<R \leq 0.84$ & Stronger & Not suitable for mining \\
Geological Environment & $0.34<R \leq 0.67$ & Ordinary & Regulating mining \\
Function, $\mathrm{B}_{3}$ & $0.17<R \leq 0.34$ & Weak & Moderate mining \\
& $R \leq 0.17$ & Weaker & Scale mining \\
\hline
\end{tabular}

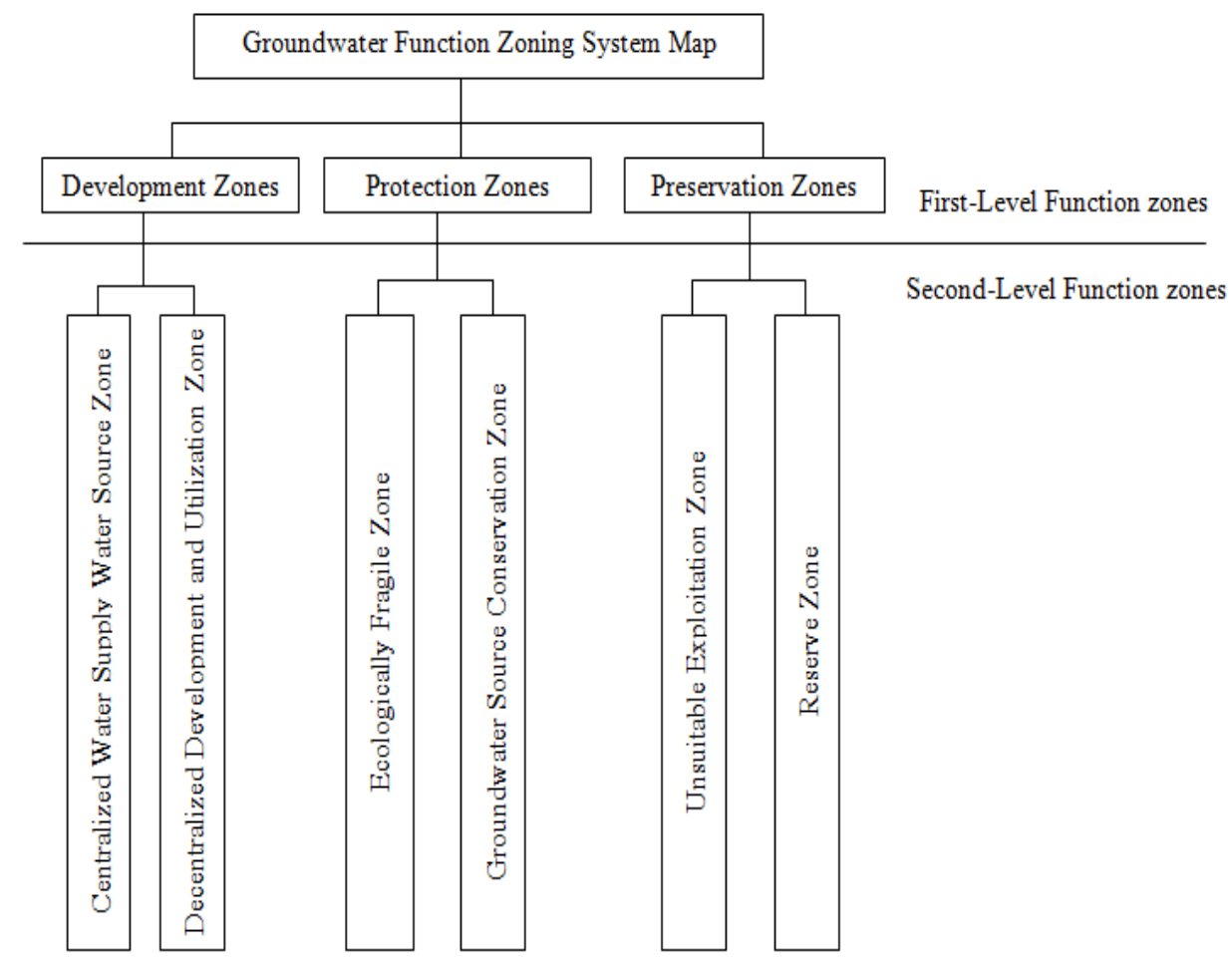

Figure 3. Functional zoning system of shallow groundwater in the study area.

The first-level groundwater function zoning was divided into three types named development zones, protection zones, and preservation zones. Within the framework of the first-level groundwater function zoning, six types of second-level function zones were divided according to the dominant groundwater function groundwater function resource. Among them:

(1) The development zones were divided into centralized water supply water source zone and decentralized development and utilization zone, Centralized water source zone refers to the groundwater centralized water supply source for drinking water or industrial production in the current situation or planning period; Decentralized development and utilization zone refers to the groundwater occurrence area that provides rural life, farmland irrigation and industrial water in small towns in a 
decentralized manner during the current situation or planning period, which is generally decentralized or seasonal exploitation.

(2) The protection zones were divided into an ecologically fragile zone and groundwater source conservation zone; ecologically fragile zone refers to areas with crucial ecological protection significance and ecosystem sensitivity to groundwater changes, including natural oasis and its marginal areas in arid and semi-arid areas, wetlands and nature reserves with important ecological protection significance. Areas prone to seawater intrusion, saltwater intrusion, ground collapse, groundwater pollution and other disasters after groundwater level decline; Groundwater source conservation zone refers to areas where groundwater exploitation is restricted to maintain specific discharge flows of important springs or to conserve water resources.

(3) The preservation zones were divided into unsuitable exploitation zone and reserve zone. Unsuitable exploitation zone refers to the area that does not have development and utilization conditions or has poor development and utilization conditions in the current situation or planning period due to poor groundwater exploitation conditions or water quality that cannot meet the use requirements; Reserve zone refers to areas with certain conditions and potential for development and utilization, but there is no large-scale development and utilization activity in the current and planning period.

\subsubsection{Shallow Groundwater Functional Zoning Score System}

The functional zoning of shallow groundwater is based on the three functional evaluation results of shallow groundwater. By comparing the functional strength relationship among resource function $\left(B_{1}\right)$, ecology function $\left(B_{2}\right)$, and geological environment function $\left(\mathrm{B}_{3}\right)$, this paper establishes the scoring system of second-level functional zoning of shallow groundwater in the study area, as shown in Table 3.

Table 3. Second-level functional zoning score system for shallow groundwater in the study area.

\begin{tabular}{|c|c|c|c|}
\hline Functional Area Type & $\begin{array}{c}\text { Advantage Function } \\
(>0.67)\end{array}$ & $\begin{array}{l}\text { Assistant Function } \\
(0.34-0.67)\end{array}$ & $\begin{array}{l}\text { Weak Function } \\
\quad(<0.34)\end{array}$ \\
\hline $\begin{array}{l}\text { Centralized Water Supply } \\
\text { Water Source Zone }\end{array}$ & $\begin{array}{c}\mathrm{B}_{1} \\
\mathrm{~B}_{1} \\
\mathrm{~B}_{1} \\
\mathrm{~B}_{1} \mathrm{~B}_{2}\end{array}$ & $\begin{array}{c}\mathrm{B}_{2} \\
- \\
\mathrm{B}_{2} \mathrm{~B}_{3} \\
\mathrm{~B}_{3}\end{array}$ & $\begin{array}{c}\mathrm{B}_{3} \\
\mathrm{~B}_{2} \mathrm{~B}_{3} \\
- \\
-\end{array}$ \\
\hline $\begin{array}{l}\text { Decentralized Development } \\
\text { And Utilization Zone }\end{array}$ & $\begin{array}{c}- \\
\mathrm{B}_{2} \\
- \\
- \\
\mathrm{B}_{2}\end{array}$ & $\begin{array}{c}\mathrm{B}_{1} \\
\mathrm{~B}_{1} \\
\mathrm{~B}_{1} \mathrm{~B}_{2} \mathrm{~B}_{3} \\
\mathrm{~B}_{1} \mathrm{~B}_{2} \\
\mathrm{~B}_{1} \mathrm{~B}_{3}\end{array}$ & $\begin{array}{c}\mathrm{B}_{2} \mathrm{~B}_{3} \\
\mathrm{~B}_{3} \\
- \\
\mathrm{B}_{3} \\
-\end{array}$ \\
\hline Ecologically Fragile Zone & $\begin{array}{l}\mathrm{B}_{2} \\
-\end{array}$ & $\begin{array}{l}- \\
\mathrm{B}_{2}\end{array}$ & $\begin{array}{l}\mathrm{B}_{1} \mathrm{~B}_{3} \\
\mathrm{~B}_{1} \mathrm{~B}_{3}\end{array}$ \\
\hline $\begin{array}{l}\text { Groundwater Source } \\
\text { Conservation Zone }\end{array}$ & - & - & $\mathrm{B}_{1} \mathrm{~B}_{2} \mathrm{~B}_{3}$ \\
\hline Unsuitable Exploitation Zone & $\begin{array}{c}\mathrm{B}_{1} \mathrm{~B}_{3} \\
\mathrm{~B}_{3} \\
\mathrm{~B}_{3} \\
\mathrm{~B}_{2} \mathrm{~B}_{3} \\
\mathrm{~B}_{1} \mathrm{~B}_{3}\end{array}$ & $\begin{array}{c}- \\
\mathrm{B}_{1} \\
\mathrm{~B}_{1} \mathrm{~B}_{2} \\
\mathrm{~B}_{1} \\
\mathrm{~B}_{2}\end{array}$ & $\begin{array}{c}\mathrm{B}_{2} \\
\mathrm{~B}_{2} \\
- \\
- \\
-\end{array}$ \\
\hline Reserve Zone & $\begin{array}{c}- \\
\mathrm{B}_{1} \mathrm{~B}_{2}\end{array}$ & $\begin{array}{c}\mathrm{B}_{1} \mathrm{~B}_{3} \\
-\end{array}$ & $\begin{array}{l}\mathrm{B}_{2} \\
\mathrm{~B}_{3}\end{array}$ \\
\hline
\end{tabular}

Note: $B_{1}$ resource function, $B_{2}$ ecology function, $B_{3}$ geological environment function, $B_{1} B_{2}$ represents the same level,- represents the minimum probability of occurrence 


\subsection{Representation Method of Distribution Results}

Geographical grid refers to the grid formed by the spatial division of the earth's surface according to certain mathematical rules or division principles, usually divided according to the regular square grid. When using the geographical grid to integrate and calculate the data, the main steps are as follows:

(1) The study area is divided into grids according to certain rules. The grids are generally divided into squares, and each grid after division is numbered.

(2) Statistically collate the data values involved in the calculation in each grid.

(3) According to the specified mathematical model or method, the data value in the grid is calculated. Finally, the target value of each grid is obtained.

(4) According to the specified classification or classification criteria, the target values in each grid are classified and divided to complete the production of visual thematic images.

\subsubsection{Evaluation Unit Demarcation}

To express the distribution characteristics of each evaluation index more accurately, this paper uses ArcGIS to divide the grid of Pingtan Island. On the grid division method and scale of the study area, through the collection and arrangement of basic data, combining with the area and stratigraphic distribution characteristics of the study area, it is determined to use ArcGIS to divide the grid of Pingtan Island. The grid-scale is $200 \times 200 \mathrm{~m}$, and the number of units is 7864 . The grid partition of the study area is shown in Figure 4.

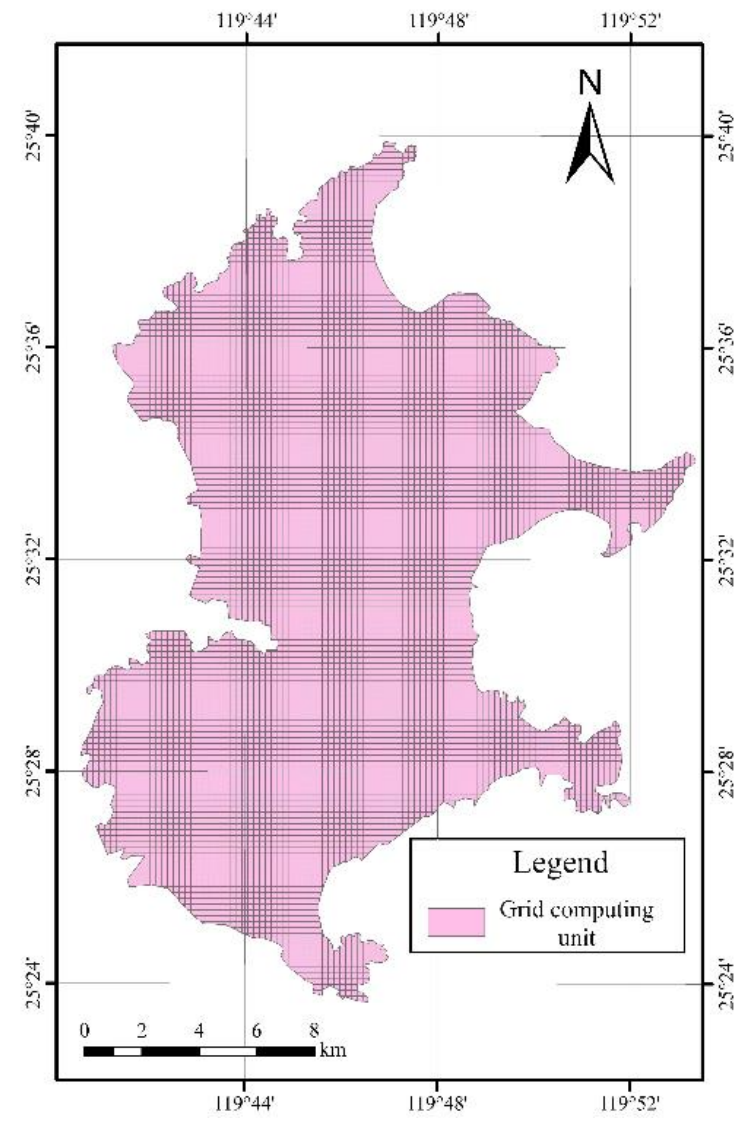

Figure 4. Research area grid subdivision diagram.

\subsubsection{Acquisition and Calculation of Evaluation Unit Data}

During the groundwater function evaluation, the following two types of data need to be processed, namely numerical data and non-numerical data. To facilitate the calculation of different data in the same evaluation system, normalization processing was made for all 
kinds of data before evaluation, converting the data into the dimensionless value between $(0-1)$. The processing method for each type of data was described as following.

For the non-numerical data, the strong-weak method was generally applied to grade division, and then the value between $(0,1)$ are directly assigned for each grade. For the numerical data, the extreme value standardization correction method was used to make the normalized data distributed in $(0,1)$.

\section{Results and Discussion}

\subsection{Groundwater Function Evaluation Results}

To systematically characterize the distribution characteristics of groundwater function in the study area, the corresponding evaluation index of each index of attribute layer and function layer was calculated, which according to the established shallow groundwater function evaluation system and comprehensive evaluation model. Then, each function evaluation index in each grid unit was calculated and the function evaluation of shallow groundwater was finally completed:

(1) Resource function evaluation. Resource function includes three attribute indexes: resource occupancy, resource regeneration, and resource availability. According to the unit data and weight of each element index corresponding to the three attribute indexes, the resource function evaluation was completed through the spatial analysis function of ArcGIS. The resource function distribution in the study area is shown in Figure 5.

(2) Ecology function evaluation. Ecology functions including three attribute indexes that landscape maintenance, vegetation environment maintenance, and land environmental relevance, according to the three attributes to the elements of the corresponding element data of indicators and the corresponding weights, through spatial overlay analysis function of ArcGIS, complete ecology function evaluation, the function of resource distribution in the study area is shown in Figure 6.

(3) Geological environment function evaluation. The geological environment function only includes the attribute index of groundwater system deterioration. According to the unit data and corresponding weight of each element index corresponding to this attribute index, the spatial superposition analysis function of ArcGIS is used to complete the geological environment function evaluation. The resource function distribution in the study area is shown in Figure 7.

(4) The dominant function evaluation of shallow groundwater. The dominant function evaluation of groundwater is to take the resource function, ecology function, and geological environment groundwater function as the research object and comprehensively reflect the distribution characteristics of the comprehensive function of shallow groundwater in the research area. Based on the objective function evaluation that ecology and geological environment functions the shallow groundwater resources in the study area, combined with shallow groundwater comprehensive function system in the study area and index weight, by using spatial data grid computing of overlay analysis, the shallow groundwater in the study area dominant function comprehensive evaluation index as shown in Figure 8. 


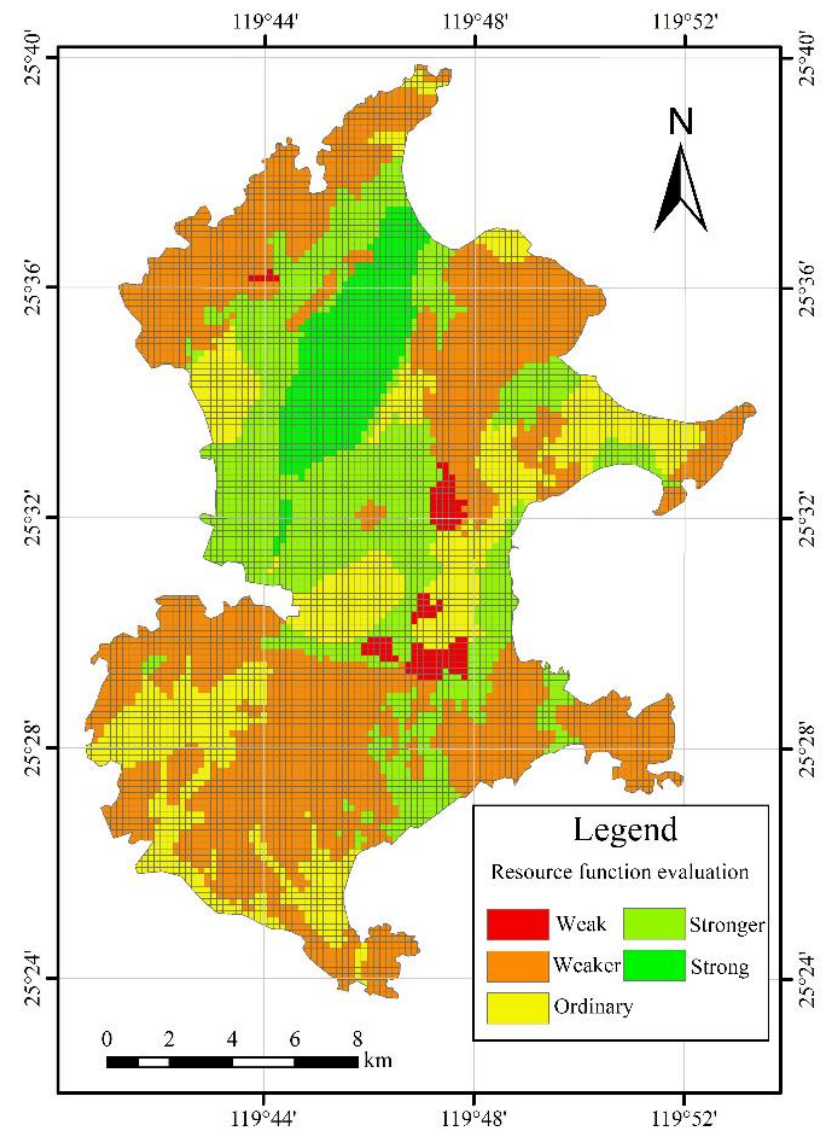

Figure 5. Evaluation results of groundwater resources function in the study area.

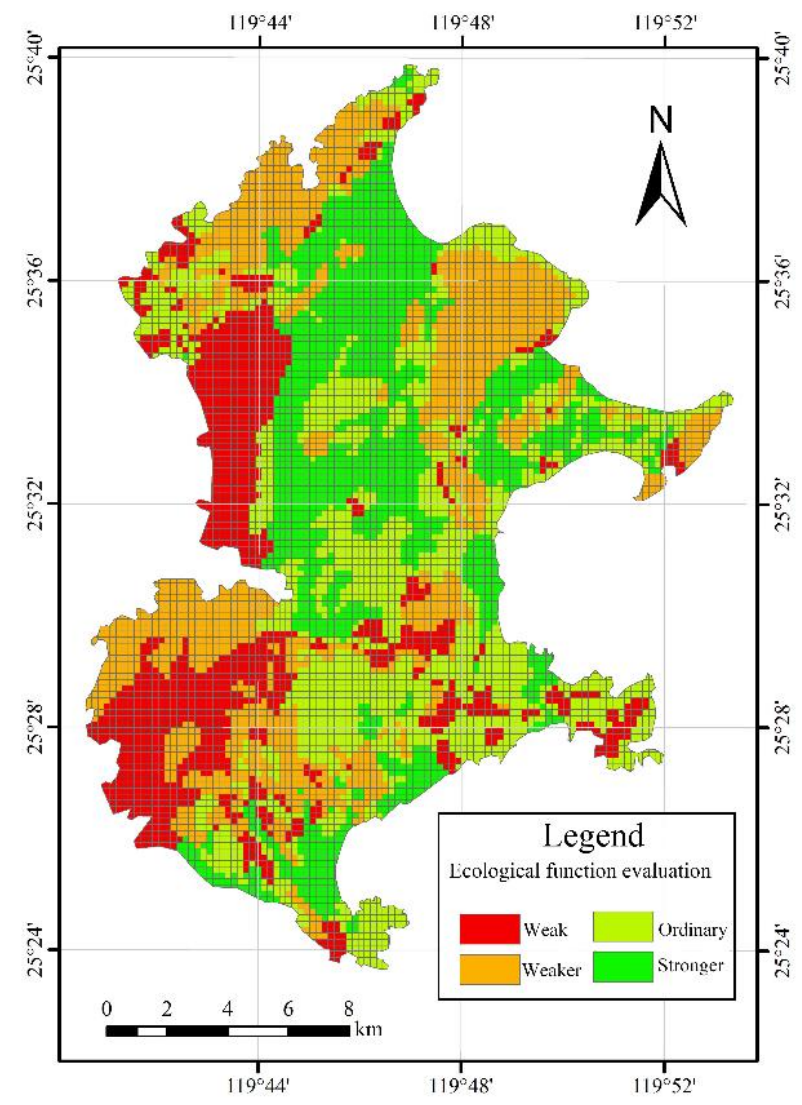

Figure 6. Assessment results of groundwater ecology function in the study area. 


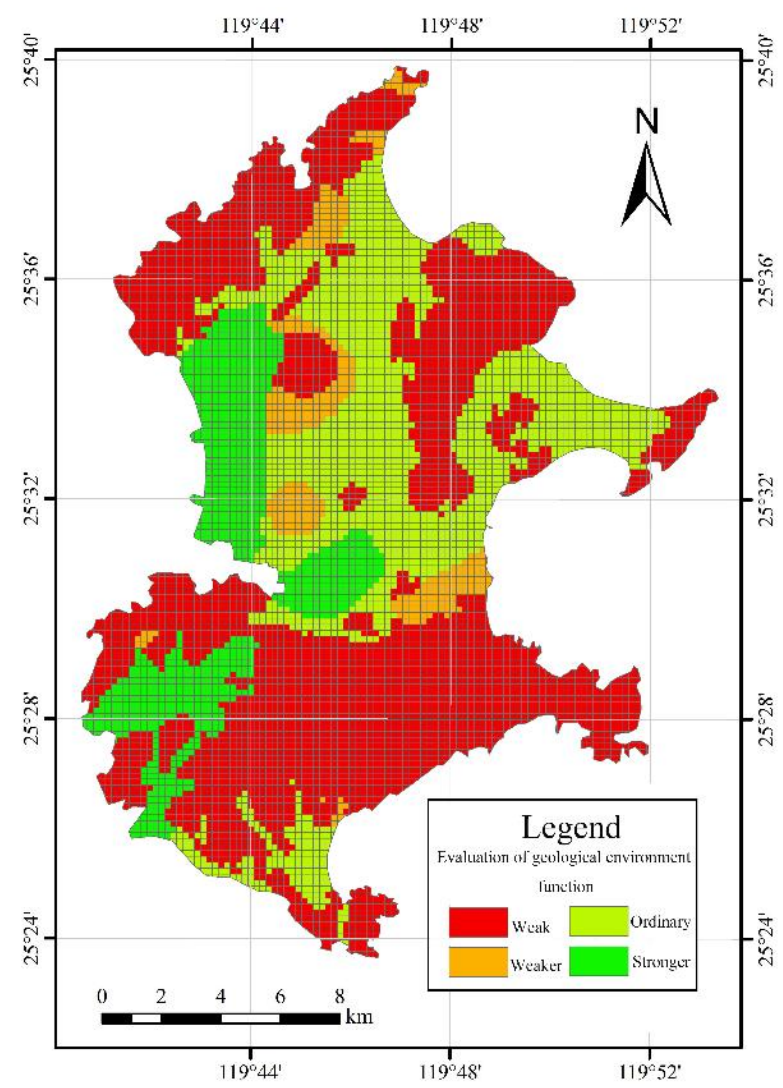

Figure 7. Assessment results of groundwater geology environment function in the study area.

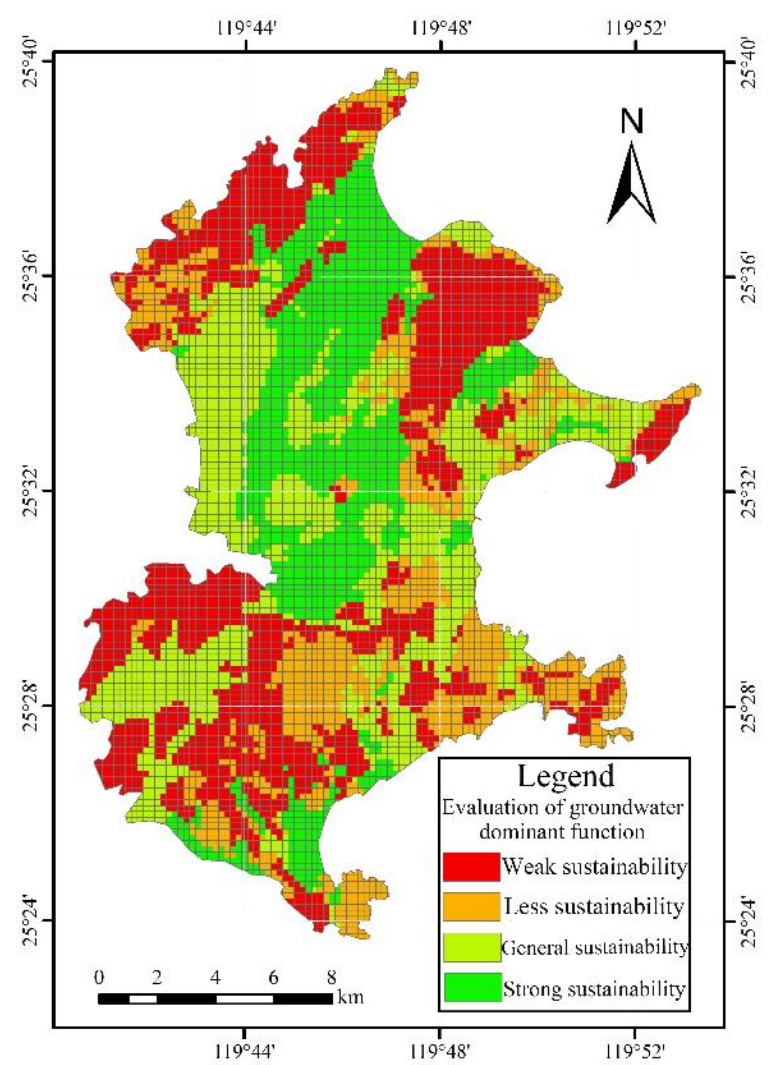

Figure 8. Distribution of comprehensive evaluation index of dominant function of shallow groundwater in the study area. 


\subsection{Groundwater Functional Zoning Results}

According to the second-level functional zoning score system of shallow groundwater in the study area, the functional zoning of shallow groundwater in the study area is shown in Figure 9.

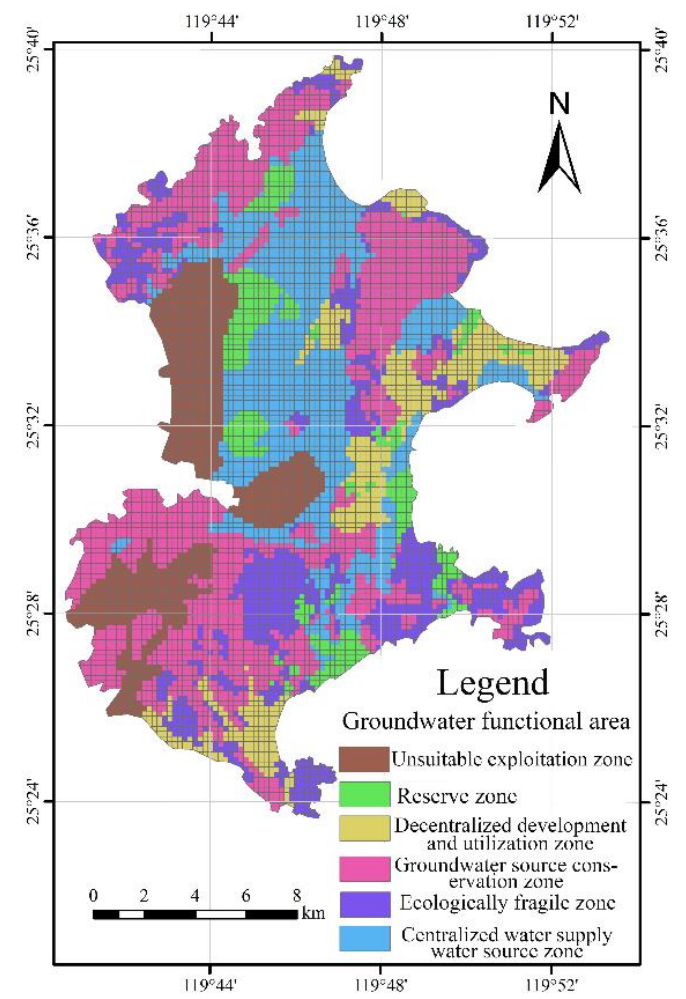

Figure 9. Functional zoning of shallow groundwater in the study area.

According to the above shallow groundwater functional zoning map, the area and proportion of each first-level and second-level functional area are calculated in this paper. The statistical results are shown in Table 4.

Table 4. Statistical table of groundwater functional areas in the study area.

\begin{tabular}{|c|c|c|c|c|c|}
\hline $\begin{array}{c}\text { First-Level } \\
\text { Functional Area }\end{array}$ & Second-Level Functional Area & Area $\left(\mathrm{km}^{2}\right)$ & Subtotal $\left(\mathbf{k m}^{2}\right)$ & $\begin{array}{l}\text { Proportion of the } \\
\text { Total Area (\%) }\end{array}$ & $\begin{array}{c}\text { Subtotal } \\
(\%)\end{array}$ \\
\hline \multirow{2}{*}{$\begin{array}{l}\text { Development } \\
\text { Zones }\end{array}$} & $\begin{array}{l}\text { Centralized water supply } \\
\text { water source zone }\end{array}$ & 62.33 & \multirow{2}{*}{90.37} & 21.12 & \multirow[b]{2}{*}{30.62} \\
\hline & $\begin{array}{l}\text { Decentralized development } \\
\text { and utilization zone }\end{array}$ & 28.04 & & 9.50 & \\
\hline \multirow[b]{2}{*}{ Protection Zones } & Ecologically fragile zone & 46.61 & \multirow[b]{2}{*}{142.99} & 15.79 & \multirow[b]{2}{*}{48.44} \\
\hline & $\begin{array}{l}\text { Groundwater source } \\
\text { conservation zone }\end{array}$ & 96.38 & & 32.65 & \\
\hline \multirow{2}{*}{ Preservation Zones } & Unsuitable exploitation zone & 41.38 & \multirow{2}{*}{61.82} & 14.02 & \multirow{2}{*}{20.94} \\
\hline & Reserve zone & 20.44 & & 6.92 & \\
\hline
\end{tabular}

It can be seen from Figure 8 and Table 4 above that:

(1) The area of a shallow groundwater development zone in the study area is 90.37 $\mathrm{km}^{2}$, accounting for $30.62 \%$ of the total study area, with relatively large exploitation potential. The concentrated water source area is $62.33 \mathrm{~km}^{2}$, accounting for $21.12 \%$ of the total study area. It is mainly distributed in Luyangpu, Lianjiupu, Longwangtoupu, and Qilipu Plain. This region is rich in groundwater resources, mainly dominated by 
resource functions that ecological and geological environment can be weakened, and large-scale exploitation can be carried out.

(2) The shallow groundwater protection area of the study area is $142.99 \mathrm{~km}^{2}$, accounting for $48.44 \%$ of the total study area. The ecologically fragile area is $46.61 \mathrm{~km}^{2}$, accounting for $15.79 \%$ of the total study area. It is mainly distributed in the south of Suao Town, Junshan, Aoqian Town, Thirty-six feet Lake Nature Reserve, and the south of Aodong Town. These regions have a strong ecological function but weak resource function and geological environment function, which need to protect the ecological environment; The groundwater source conservation area is $96.38 \mathrm{~km}^{2}$, accounting for $32.65 \%$ of the total study area. It is mainly distributed in the hilly bedrock area of the study area, where all the target functions of groundwater are in a weak state, Still these areas have important ecological significance and have a conservation effect on groundwater. The measures of moderate exploitation, regulating exploitation, and limited exploitation should be carried out for the groundwater resources inreserve and should strengthen ecological environment protection and control measures.

(3) The shallow groundwater reserve area of the study area is $61.82 \mathrm{~km}^{2}$, accounting for $20.94 \%$ of the total study area. The unsuitable mining area is mainly distributed in the reclamation area. The geological environment function of these areas is strong, the resource function and ecological function are weak. Although they have certain resource potential, the water quality is very poor, and the exploitation is easy to cause geological disasters such as sea salt water invasion, so it is not suitable to carry out groundwater exploitation in these areas; The reserve area is $20.44 \mathrm{~km}^{2}$, accounting for $6.92 \%$ of the total study area, mainly distributed in the west of Luyangpu and the south of Qilipu, These areas have both resource function and ecology function or both resource function and geological environment function, which have groundwater development conditions and potential. However, the ecology and geological environment in these areas need to be protected, and groundwater exploitation can also cause the geology and ecological environmental problems. The exploitation of these areas can be restricted, and effective ecology and geological environment protection measures should be taken.

\subsection{Validation of Zoning Results}

This paper selects the distribution map of water yield property in the study area to verify the zoning results.

According to the occurrence conditions of shallow groundwater in Pingtan Island, the groundwater can be divided into loose rock pore water and bedrock fissure water;according to the water yield property, the shallow groundwater in Pingtan Island is classified. The classification of shallow groundwater types and water yield property in Pingtan Island is shown in Figure 10.

It can be seen from Figure 9 that in the pore water of loose rocks, the water-rich regions are mainly divided into Luyangpu, Qilipu, Lianjiupu, and Longwangtoupu. The water-rich grade is the area with medium water volume, mainly distributed in the plain (Guanjing), Dawopu, Zhifengyang, Yanxiapu, Cangxiayang, Dongkunyang, and Yangzhongyangpu. The water-rich regions were mainly distributed in hilly valleys in Aodong, Suao, Baiqing, and Tandong.The water-rich grade of bedrock fissure is all water-poor area, mainly distributed in Suao, Baiqing, Junshan, Beicuo, Aodong, Aoqian, and other places.

Comparing the functional zoning map of shallow groundwater in the study area and the grade distribution map of shallow groundwater water enrichment in Pingtan Island. The occurrence area of pore water in loose rocks with abundant water is the same as that in centralized water supply source area. The dispersed development and utilization area are the same as the loose rock pore water area with medium water yield; The groundwater conservation area is consistent with that of bedrock fissure water.

The above comparison results show that the shallow groundwater function zoning results in this paper have high reliability. 


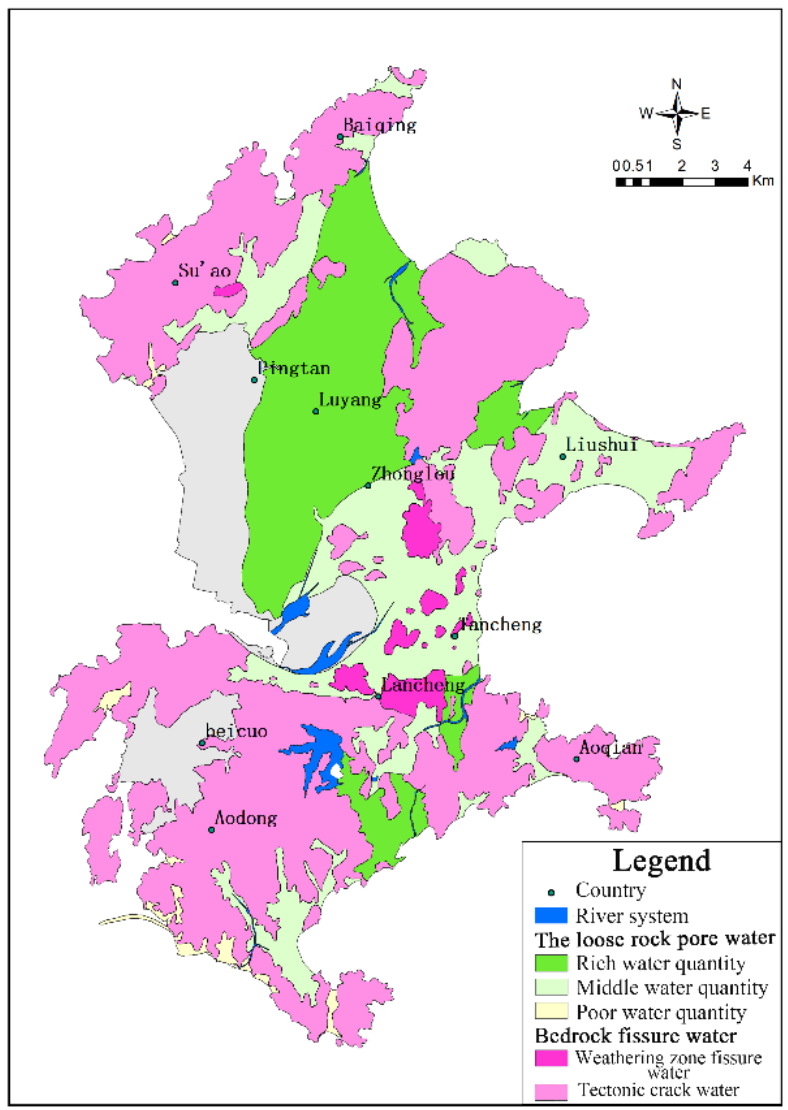

Figure 10. Distribution of shallow underground water yield property in Pingtan Island.

\section{Summary}

(1) According to the division result of groundwater function zones in Pingtan Island, the area of groundwater development zone accounts for about $1 / 3$ of the study area, mainly distributed in plain areas. Although these areas have certain exploitation potential, villages and farmland are widely distributed, leading to the large demand for agricultural and domestic water. In water resource utilization, problems such as groundwater over-exploitation and groundwater resource pollution should be avoided so that the groundwater resources in the region can be sustainably developed and utilized.

(2) The area of groundwater protection area in Pingtan Island accounts for about 1/2 of the study area, which is mainly distributed in the hilly area and reservoir distribution area. These areas have important ecological significance and a conservation effect on groundwater. The exploitation and utilization of groundwater in these areas should be restricted, and ecological environment protection and control measures should be strengthened to avoid deforestation.

(3) Pingtan Island's groundwater reserve area accounts for about 1/5 of the study area; the area is relatively small. For the reclamation area, seawater intrusion area, and huoshaogang salt field, the government should limit the exploitation of groundwater resource and strengthen the monitoring of groundwater level and water quality to avoid the expansion of unsuitable mining areas.

\section{Conclusions}

With the support of GIS spatial analysis technology, this paper divides the shallow groundwater function areas of Pingtan Island and draws the following conclusions:

(1) According to the technical requirements, the functional zoning is mainly applicable to the Quaternary groundwater system in Northwest China, North China, and Northeast 
China. Selecting Pingtan Island as the research object and applying it to the island area for the first time, this paper analyzes the selection of evaluation factors in the island area, a set of functional zoning methods suitable for groundwater management in small islands watershed are summarized.

(2) In this paper, the groundwater function zoning method takes the groundwater function evaluation as the entry point. It the combines the groundwater function evaluation results with the groundwater function zoning system and finally realizes the groundwater function zoning in the study area.

(3) Compared with the zoning method in the Technical Outline of Groundwater Function Zoning issued by the Ministry, which has the advantages of perfect theory, high precision and suitable for small island regionalization, and avoids the deficiency of less regionalization index, more qualitative description and poor regionalization precision.

This paper presents a zoning method suitable for islands: Firstly, the resource function, ecology function, and geological environment function of shallow groundwater in the Island are evaluated, and the distribution characteristics and strong relationship of each function in the study area are obtained. According to the development and utilization of groundwater resources in the study area, the secondary system of shallow groundwater function zoning is established. By constructing the scoring system for the functional zoning of shallow groundwater, the corresponding relationship between the functional zones of shallow groundwater and the three functional characteristics of shallow groundwater is established, and the functional zoning of shallow groundwater is finally completed.

Author Contributions: This paper was composed by collaboration among all authors. W.L. designed this study, provided the method, and revised the manuscript. X.T. carried out the data analysis and prepared the first draft of the manuscript. P.L. and Y.L. supported this manuscript. All authors have read and agreed to the published version of the manuscript.

Funding: This work was financially supported by the Shandong Provincial Natural Science Foundation, China (ZR2019MEE106), the Shandong Province Science and Technology Development Plans (2013GSF11606).

Institutional Review Board Statement: Not applicable.

Informed Consent Statement: Not applicable.

Data Availability Statement: Data sharing not applicable.

Acknowledgments: All authors are very grateful to the editor and anonymous reviewers for their valuable comments. The authors thank the water department of Fuzhou city for providing groundwater data.

Conflicts of Interest: The authors declare no conflict of interest.

\section{References}

1. Li, Z.H. Ideas and allocation scheme of groundwater resources development and protection. China Resour. Compr. Util. 2017, 35, 38-40. (In Chinese)

2. Liu, D.W.; Zhang, S. Impact of groundwater exploitation on ecological environment and countermeasures. Groundwater 2018, 40, 53-55. (In Chinese)

3. $\mathrm{Xu}$, Z.R. Preliminary study on the division of groundwater function zones. Hydrogeol. Eng. Geol. 1998, 5, 45-46. (In Chinese)

4. Shi, R.Q.; Sun, W.F. Application of grey clustering analysis in groundwater function zoning. Eng. Investig. 1999, 1, 27-30. (In Chinese)

5. Tang, K.W.; Du, Q. Division of groundwater function zones. Water Resour. Protect. 2004, 20, 16-19. (In Chinese)

6. Liu, J.F.; Li, S.; Ren, C.Y.; Wang, Z.; Zhang, B. Study on the division of groundwater functional zones in Jilin Province. Resour. Environ. Arid Areas 2018, 32, 159-165. (In Chinese)

7. Cao, Y.; Teng, Y.G.; Wang, J.S.; Zhai, Y.; Zheng, J. Division of groundwater functional zones in Quanzhou City. Acta Geosci. Sin. 2011, 32, 469-476. (In Chinese)

8. Jha, M.K.; Chowdhury, A.; Chowdary, V.M.; Peiffer, S. Groundwater management and development by integrated remote sensing and geographic information systems: Prospects and constraints. Water Resour. Manag. 2007, 21, 427-467. [CrossRef]

9. Carrera-Hernández, J.J.; Gaskin, S.J. Water management in the Basin of Mexico: Current state and alternative scenarios. Hydrogeol. J. 2009, 17, 1483-1494. [CrossRef] 
10. Feinerman, E.; Knapp, K.C. Benefits from Groundwater Management: Magnitude, Sensitivity, and Distribution. Am. J. Agric. Econom. 1983, 65, 703-710. [CrossRef]

11. Burke, J.J.; Moench, M.H. Groundwater and Society: Resources, Tensions and Opportunities. Themes in Groundwater Management for the Twenty-First Century; CAB Direct: New York, NY, USA, 2000.

12. Fernández-Mejuto, M.; Andreu, J.M.; García-Sánchez, E.; Palencia, R. An Assessment of Groundwater Recharge at a Regional Scale for Sustainable Resource Management: Province of Alicante (SE Spain). Water 2021, 13, 862. [CrossRef]

13. Zhu, Q.; Abdelkareem, M. Mapping Groundwater Potential Zones Using a Knowledge-Driven Approach and GIS Analysis. Water 2021, 13, 579. [CrossRef]

14. Lyra, A.; Loukas, A.; Sidiropoulos, P.; Tziatzios, G.; Mylopoulos, N. An Integrated Modeling System for the Evaluation of Water Resources in Coastal Agricultural Watersheds: Application in Almyros Basin, Thessaly, Greece. Water 2021, 13, 268. [CrossRef]

15. Fujian Development and Reform Commission. Overall Development Planning of Pingtan Comprehensive Experimental Zone; Strait Literature and Art Press: Fuzhou, China, 2012.

16. Ministry of Water Resources of the People's Republic of China. Technical Outline for Division of Groundwater Function Zones; Ministry of Water Resources of the People's Republic of China: Beijing, China, 2005.

17. Fujian Geological Survey Research Institute. Report of 1:50,000 Hydrogeological and Engineering Geological Survey Results in Pingtan County, Fujian Province; Fujian Geological Survey Research Institute: Fuzhou, China, 2011.

18. Li, Y.; Shu, L.; Zhen, L.; Li, H.; Wang, R.; Opoku, P.A. Laboratory Physical Experiments on the Saltwater Upconing and Recovery of Island Freshwater Lenses: Case Study of a Coral Island, China. Water 2021, 13, 1137. [CrossRef]

19. Li, Y.; Li, W.; He, J.; Zhang, H.; Li, X. Infiltration and Anti-Filtration Recharge-Pumping Well and Laboratory Recharge Tests. Water 2018, 10, 1834. [CrossRef] 